\title{
A embriaguez mortífera do canto neoliberal da sereia pós-moderna capitalista
}

\section{Roberto Kennedy Gomes Franco}

Prof. Dr. Roberto Kennedy Gomes Franco. Universidade da Integração Internacional da Lusofonia Afro-Brasileira-Unilab. Coordenador do GIM - Grupo Interdisciplinar Marxista. E-mail: robertokennedy@unilab.edu.br

\section{RESUMO}

O texto A Embriaguez mortífera do canto neoliberal da sereia pós-moderna capitalista é fruto de minha fala no X Seminário Internacional de Luta contra - Neoliberalismo, com o tema: "A Crise do Capital: Guerra imperialista e Golpe neoliberal". Dialeticamente analiso as contradições históricas da chamada pós-modernidade enquanto lógica cultural das relações sociais que os indivíduos estabelecem no modo de produção do capitalismo tardio. Parto da tese de que, articulado às peculiaridades da lógica capitalista, o discurso pós-moderno ao tempo em que relativiza a luta de classes, encantando e seduzindo como o canto das sereias narrados por Homero na Odisseia, dionisiacamente, embriagam negativamente as necessidades humanas para a reprodução da sociabilidade do Capital, ou seja, do individualismo e da exploração entre os seres humanos, fato este que concretamente pauperiza e potencializa o sofrimento de um sem fim de pessoas nas masmorras da miséria. Para tanto, a realidade é pintada ilusoriamente como se bem deseja, num jogo linguístico, estético e poético que seduz e aliena, transvalorando princípios sociais, morais, éticos, etc. Segundo os preceitos epistemológicos disso que o mercado capitalista tem vendido como novo, ou seja, o imperialismo ideológico pós-moderno, qualquer promessa de justiça social e emancipação humana é um projeto falido, a realidade é o que eu individuo digo ser real, a racionalidade, o cientificismo uma quimera que não se concretizaram. Conforme os apologistas da pós-modernidade, o real é o que digo ser real, minha ideia de real é que faz forma e significado, esta volta grosseira ao idealismo hegeliano, com uma escrita da história meramente descritiva e narrativa, com ênfase ao subjetivismo, torna ainda mais fragmentada qualquer possibilidade de organização, luta e resistência. Nesta linha de raciocínio, conhecer em seus pormenores as contradições da chamada pós-modernidade é importante para formar nossa consciência histórica acerca da necessidade da luta anticapitalista e de declaração de guerra à disseminação de uma praga teórica que assim como as ervas daninhas, se alastram, se capilarizam nefastamente na vida cotidiana. Estes aspectos são fundamentais para uma 
pesquisa engajada e comprometida com as necessárias transformações das mazelas sociais vigentes em nosso tempo.

Palavras-chave: História; Educação; Pós-modernidade e Anticapitalismo.

\section{ABSTRACT}

The text A Embriaguez mortífera do canto neoliberal da sereia pós-moderna capitalista is the result of my speech on the $X$ Seminário Internacional de Luta contra o Neoliberalismo, with the theme: "A Crise do Capital: Guerra imperialista e Golpe neoliberal". Dialectically analyze the contradictions historical cultural postmodernity as logic called the social relations that individuals establish the capitalist mode of production later. Thesis calving that articulated to the peculiarities of capitalist logic, the postmodern discourse at the time that relativize the fight classes, charming and enticing as the song of the Sirens narrated by Homer in the Odyssey, Dionysian, negatively drunk human needs for reproduction of sociality of capital, ie, of individualism and exploitation of human beings, a fact that particularly impoverishes and leverages the suffering of a myriad of people in the dungeons of poverty. For this, the reality is deceptively painted as if I want to, in a linguistic, aesthetic and poetic game that seduces and alienates, changing social, moral, ethical principles, etc. According to the precepts epistemological that the capitalist market has sold as new, or the postmodern ideological imperialism, any promise of social justice and human emancipation is a failed project, the reality is what I individual say is real, rationality, scientism a chimera that did not materialize. As apologists of postmodernism, the real is what I say is true, my idea of real is what makes form and meaning, this rough back to Hegel's idealism, with a writing merely descriptive history and narrative, with emphasis on subjectivism, It makes it even more fragmented any possibility of organization, struggle and resistance. In this line of reasoning, known in its details the postmodern call contradictions is important to form our historical consciousness about the need of anti-capitalist struggle and declaration of war to the spread of a theoretical plague that just as weeds, rage on ominously in everyday life. These aspects are fundamental to research an engaged and committed to the necessary transformation of current social ills in our time.

Keywords: History; Education; Postmodernity and Anticapitalism.

\section{RESUMEN}

El texto A Embriaguez mortífera do canto neoliberal da sereia pós-moderna capitalista es el resultado de mi intervención en el X Seminário Internacional de Luta contra o Neoliberalismo, con el tema: "A Crise do Capital: Guerra imperialista e Golpe neoliberal". Analizo dialécticamente las contradicciones de la posmodernidad histórico cultural como la lógica llama las relaciones sociales que los individuos establecen el modo de producción capitalista más tarde. Parición tesis de que articula a las peculiaridades de la lógica capitalista, el discurso posmoderno en el momento que relativizar la lucha clases, encantadores y atractivos como el canto de las sirenas narrados por Homero en la Odisea, las necesidades humanas dionisíacos, negativamente borrachos para la reproducción de la socialidad del capital, es decir, del 
individualismo y la explotación de seres humanos, un hecho que todo pauperiza y aprovecha el sufrimiento de una gran cantidad de personas en los calabozos de la pobreza. Para ello, la realidad se describe engañosamente como si yo quiero, en un juego lingüístico, estético y poético que seduce y aliena, y cambia principios sociales, morales, éticos, etc. De acuerdo con los preceptos epistemológicos que el mercado capitalista ha vendido como nuevo, o el imperialismo ideológico postmoderno, cualquier promesa de justicia social y la emancipación humana es un proyecto fallido, la realidad es lo que digo individuo es real, la racionalidad, cientificismo una quimera que no se materializó. Como defensores de la posmodernidad, lo real es lo que digo es cierto, mi idea de la propiedad es lo que hace que la forma y el significado, esta áspera volver al idealismo de Hegel, con una escritura de la historia y la narrativa meramente descriptivo, con énfasis en el subjetivismo, Esto hace que sea aún más fragmentado cualquier posibilidad de organización, lucha y resistencia. En esta línea de razonamiento, conocida en sus detalles las contradicciones de llamadas posmodernas es importante para formar nuestra conciencia histórica acerca de la necesidad de la lucha anti-capitalista y la declaración de guerra a la propagación de una plaga teórico que, así como las malas hierbas, rabia encendido, si propagan ominosamente en la vida cotidiana. Estos aspectos son fundamentales para la investigación de un comprometidos y comprometidas con la transformación necesaria de los males sociales actuales en nuestro tiempo.

Palabras clave: Historia; Educación; La postmodernidad y Anticapitalismo. 
Este texto é fruto de minha fala no X Seminário Internacional de Luta contra o Neoliberalismo, com o tema: "A Crise do Capital: Guerra imperialista e Golpe neoliberal”, além de ser uma provação ao debate, é antes de qualquer coisa, parte de meu engajamento/combate na luta anticapitalista. Busco analisar, dialeticamente, a historicidade da pós-modernidade no contexto do modo de produção capitalista tardio. Este processo é entendido não somente como produção de determinado tipo de saber-poder, mas também como lugar de aprendizado político acerca da história da luta de classes.

Articulado aos interesses da lógica capitalista de manutenção de índices desiguais de desenvolvimento social, em meu entender, a pós-modernidade tem relação imediata com as peculiaridades do contexto histórico-educativo brasileiro de transição do século XX para o XXI. Portanto, o texto A Embriaguez mortífera do canto neoliberal da sereia pós-moderna capitalista é uma reafirmação de minha declaração de guerra aos preceitos epistemológicos disso que o mercado capitalista tem vendido como novo, ou seja, o pensar-fazer pós-moderno.

Eric Hobsbawm (1998) e Pierre Vilar (1987), historiadores marxistas, já haviam denunciado isso, no que diz respeito à relação do mercado editorial capitalista ter transformado os historiadores em estrelas famosas e consumidas por mercado leitor, ávido por histórias assépticas, degustáveis.

Essa virada para a chamada nova história cultural, focada na diversidade da cultura, transforma o cultural numa refinada mercadoria para a grande indústria capitalista. Histórias que dionisiacamente, embriagam ao tempo em que relativizam a luta de classes, encantando e seduzindo como o canto das sereias.

E por falar em sereias...

Diz a lenda que esse ser mitológico tem em parte de seu corpo a formosura de uma sensual e deliciosa mulher e a outra parte a forma de peixe. São tão lindas e encantadoras que a doçura da sonoridade de seu canto de forma potente e desejante inebriariam mortalmente aos sentidos dos ouvintes.

$\mathrm{Na}$ tradição filosófica grega, temos na figura de Odisseu um bom exemplo disso. $\mathrm{Na}$ narrativa da Odisseia de Homero (2000), Odisseu conseguiu salvar-se porque pôs cera nos ouvidos dos seus marinheiros e amarrou-se ao mastro de seu navio, para poder vê-las, sem ouvi-las e assim aproximar-se.

Assim, em minhas hipóteses, o saborear o canto da sereia materializa-se naquilo que Nietzsche (1983), apreciador da música, falava sobre a "perigosa travessia", ou seja, o canto da sereia é uma ilusão, um jogo de vida elou de morte que na sociabilidade do capital no século XXI, transmuta-se na ideologia pós-moderna.

Isto porque na sociabilidade do capital, as leis de mercado se materializam mediante relações sociais onde cotidianamente a regra do viver é pura e simplesmente a exploração entre os seres humanos, fato este que concretamente pauperiza e potencializa o sofrimento de um sem fim de pessoas mundo afora.

Metaforicamente, esse jogo linguístico, ilusionista/alienador, bem ao gosto dos pós-modernos, similar ao canto das sereias, manifesta também a disseminação de uma praga, que assim como as ervas daninhas, se alastram, se capilarizam na vida cotidiana, e em especial, na minha experiência de Professor Universitário.

Daí minha articulação com o tema do evento, ou seja, a luta contra o neoliberalismo. Em minha experiência na docência do ensino superior, fui surpreendido por 


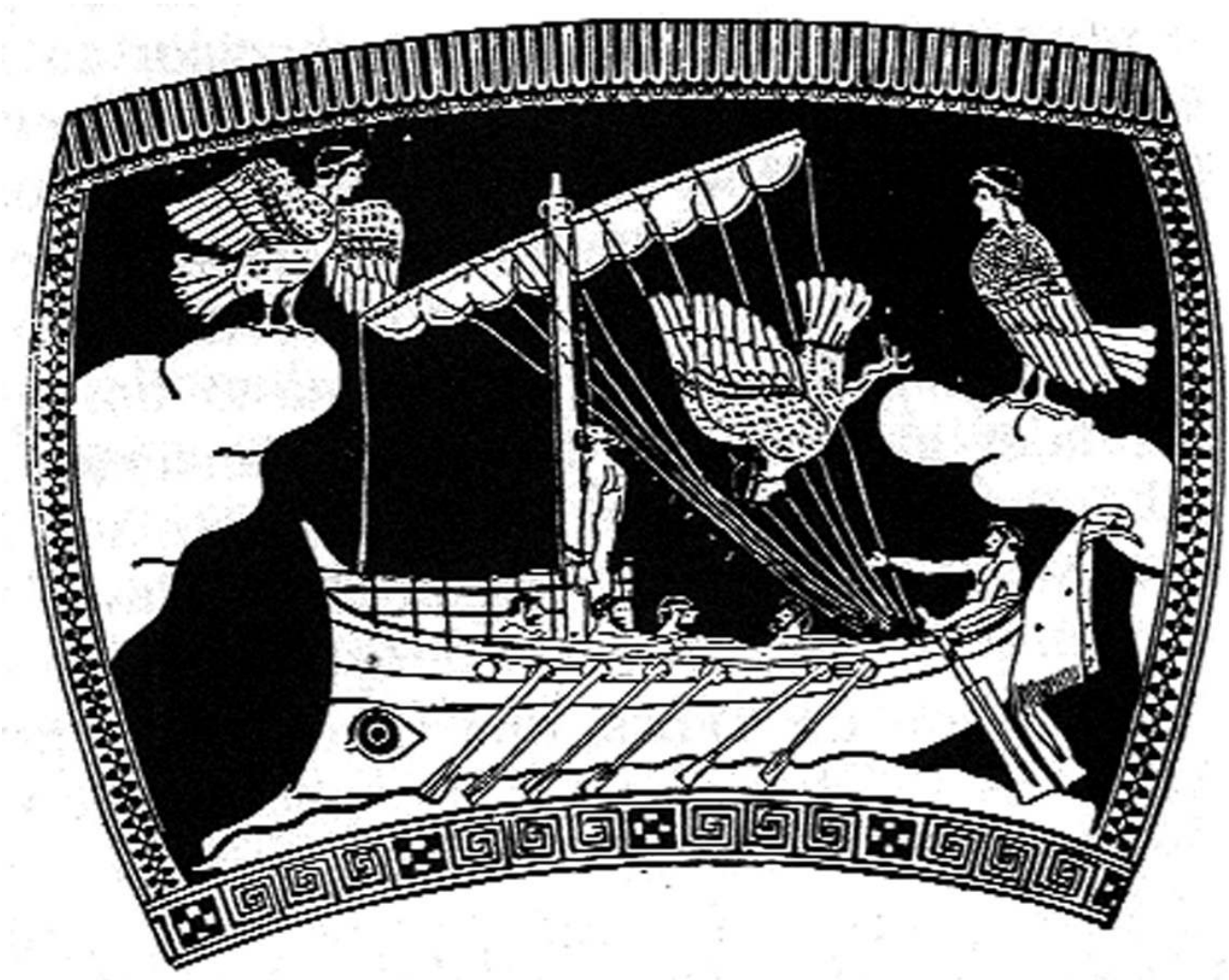

Ulisses e as sereias. Fonte: https://meninasemarte. wordpress.com/tag/resumo-iliada-e-odisseia/.

uma realidade na qual até mesmo o fato de me reivindicar marxista, ou praticante do materialismo histórico-dialético, soa como algo esdrúxulo, primitivo, superado.

Isto porque a ação educativa desenvolvida naquele espaço encontrava-se intimamente implicada neste emaranhado sistêmico, no qual turbilhões de interesses capitalistas permeiam de significados os desejos humanos, materializados numa sociabilidade baseada no estranhamento e numa lógica antissocial, respaldada por um modelo educacional que se reivindica pós-moderno, sendo na verdade comprometido com a ideologia hegemônica do Capital. Os preceitos educacionais, salvo exceções, nesse sentido, validam ensinamentos que reproduzem ações de exploração entre os seres humanos e dilapidação do coletivo em favor do individual.

Então, quer dizer que esta realidade local se conecta transnacionalmente com o debate em torno das teorias da história, por exemplo, categoricamente, classificam o marxismo como algo superado, nas falas dos alunos chamava atenção o fato de alguém ter feito um doutorado ainda falando sobre isso, um método cíclico, autoritário, economicista, determinista, reducionista, superado, e uma série outra de adjetivos preconceituosos que findaram nas delegacias de polícia, em vista de ataques pessoais que nós do Grupo de Estudos Marxistas sofremos ao longo desse tempo de história de luta e resistência.

Entrincheirados neste front, nos organizamos autonomamente em torno da luta de classes, que em nosso entender se materializaria na luta por melhores condições de vida, as mais diversas, por mais que se afirme que a fome, por exemplo, é apenas uma enunciação discursiva, assim como a luta de classes, uma abstração sem sentido.

A luta por uma Universidade verdadeiramente Pública, Gratuita de Qualidade um devaneio, pois para nossos golpistas inimigos de classe, a Universidade vai bem. 
Basta vermos os mais recentes dados estatísticos de ingresso pelo ENEM, e ainda, os resultados manipulados do ENADE.

Assim, a realidade é pintada ilusoriamente como se bem deseja, num jogo estético e poético que seduz, encanta e ilude, assim como as sereias, transvalorando princípios morais, éticos. Qualquer projeto de sociedade, qualquer promessa de justiça social é um projeto falido, a realidade é o que eu individuo digo ser real, a racionalidade, o cientificismo uma quimera que não se concretizaram.

Para estes apologistas da pós-modernidade, o real é o que digo ser real, minha ideia de real é que faz forma e significado, esta volta grosseira ao idealismo hegeliano, com uma escrita da história meramente descritiva e narrativa, com ênfase no subjetivismo, torna ainda mais fragmentada qualquer possibilidade de organização, luta e resistência para aqueles que estudam a história e a vivem em sua dialeticidade.

Neste contexto de reestruturação produtiva, dissolução das leis trabalhistas, toyotismo, just in time, a educação e a história, assim como a vida, são líquidas. Reduz-se a educação e a história a um mero meio para servir o mercado e, assim, os sujeitos influenciados por esta lógica cultural não se perguntam sobre o papel social e conscientizador da educação.

Neste sentido, Fredric Jameson (2002) afirma ser o pós-modernismo a lógica cultural do capitalismo tardio, e ainda, sobre sua compreensão conceitual de indústria cultural na obra o marxismo tardio, diz o seguinte: "A indústria cultural não é uma teoria da cultura, mas a teoria de uma indústria, de um ramo dos inter-relacionados monopólios do capitalismo tardio que fazem dinheiro a partir do que se costumava chamar de cultura." (JAMESON, 2002).

Assim o holocausto produzido pelo nazismo, a escravidão negra e indígena produzida pelo colonialismo mercantil, o tsunami, a miséria social, as experiências de adoecimento como a Sida/Aids, tudo discurso. Inclusive a sua vontade de estuprar uma pessoa, ou quem sabe o que mais...

Não obstante, o mais impressionante é que essa caricatura de si mesmo, que são os ditos pós-modernos ao qual combatemos é frágil e boba, muitas vezes até equivocada em relação ao movimento filosófico mais amplo em que se insere essa tal pós-modernidade e sua relação com o marxismo. Vejamos nas palavras de Foucault (2001), no livro A Microfísica do poder, no texto sobre a prisão.

Atentai bem:

"Magazine Littéraire: em relação a Marx e ao marxismo você parece manter uma certa distância, o que já lhe havia sido dito como crítica a propósito da arqueologia do saber.

M.F.: sem dúvida, mas há também de minha parte uma espécie de jogo. Ocorre-me freqüentemente citar conceitos, frases e textos de Marx, mas sem me sentir obrigado a acrescentar a isto a pequena peça autentificadora que consiste em fazer uma citação de Marx, em colocar cuidadosamente a referência de pé de página, e em acompanhar a citação de uma referência elogiosa, por meio de que se pode ser considerado como alguém que conhece Marx, que reverencia Marx e que se verá honrado pelas revistas ditas marxistas. Cito Marx sem dizê-lo, sem colocar aspas, e como eles não são capazes de reconhecer os textos de Marx, passo por ser aquele que não cita Marx. Será que um físico, quando faz física, experimenta a necessidade de citar Nerwton ou Einstein? Ele os utiliza, mas não tem necessidade de aspas, de nota de pé de página ou de aprovação elogiosa que prove a que ponto ele é fiel ao pensamento do mestre. E como os demais físicos sabem o que fez Einstein, o que ele inventou e demonstrou, o reconhecem imediatamente. 
E impossivel fazer história atualmente sem utilizar uma seqüência infindável de conceitos ligados direta ou indiretamente ao pensamento de Marx e sem se colocar num horizonte descrito e definido por Marx. Em última análise poder-se-ia perguntar que diferença poderia haver entre ser historiador e ser marxista". (FOUCAULT, 2001).

Parece piada, ou uma montagem, mas não é, um dos grandes expoentes dessa tradição, Foucault, quase um semideus, citado e ovacionado por muitos, reconhece claramente a importância e influência de Marx.

Um outro aspecto nos chama atenção ainda, trata-se do debate desenvolvido por Eric Hobsbawm (1998) em seu livro sobre a história, no artigo chamado Engajamento, onde fala do papel social do pesquisador em contribuir para a emancipação humana. Em tempos pós-modernos, se é que existe esse tempo, isso é impossível.

De forma complementar para Terry Eagleton a Pós-Modernidade é:

(...) "uma linha de pensamento que questiona as noções clássicas de verdade, razão, identidade e objetividade, a idéia de progresso ou emancipação universal, os siste mas únicos, as grandes narrativas ou os fundamentos definitivos de explicação. Contrariando essas normas do iluminismo, vê o mundo como contingente, gratuito, diverso, instável, imprevisivel, um con junto de culturas ou interpretaçôes desunificadas gerando um certo grau de ceticismo em relação à objetividade da verdade, da bistória e das normas, em relação às idiossincrasias e a coerência de identidades". (EAGLETON, 1998, p. 7).

Assim a pós-modernidade enquanto reflexão filosófica se articula "com a mutação da sociabilidade do capital e da indústria cultural no final do século XX" (EAGLETON, 1998, p. 7). Para Fredric Jameson (2002), o postulado golpista do discurso pós-moderno nada mais seria que a lógica cultural do capitalismo tardio ou do também chamado capitalismo pós-industrial. Com o deslocamento de uma ética do trabalho para uma ética de consumo, os valores sociais e de identidade passam a ser os do individualismo, transitoriedade, flexibilidade, inconstância, efemeridade, fragmentação, ausência de regras, de padrões e de limites.

Essa ênfase ao individualismo o pós-moderno se articula com os interesses da lógica capitalista de manutenção de índices desiguais de desenvolvimento social, e ainda, em meu entender, este processo tem relação também com as peculiaridades do contexto histórico-educativo transnacional de transição do século XX para o XXI.

Assim, chego a uma questão essencial em minhas análises, ou seja, a da inspiração/ associação ideológica da pós-modernidade com a Teoria do Capital Humano ${ }^{1}$ e neoliberal. Meu objetivo portanto é argumentar que o pensamento/fazer, a enunciação discursiva e a ação política da "agenda pós-moderna" (WOOD, 1990), são articuladas com o momento histórico-educativo do chamado neoliberalismo.

1A Teoria do Capital Humano, presente no pensamento liberal desde Adam Smith, foi alvo dos estudos de Schultz, Prêmio Nobel de Economia, que, no pós-guerra, pesquisou a rápida recuperação da Alemanha e do Japão, comparando a situação desses países à do Reino Unido, onde ainda havia racionamento de alimentos muito tempo depois da guerra. Concluiu que a velocidade de recuperação decorreria de uma população saudável e altamente educada. Segundo ele, a educação torna as pessoas produtivas e a boa atenção à saúde aumenta o retorno do investimento em educação. Assim, introduziu a ideia de "capital educacional", relacionando-o especificamente aos investimentos em educação. 
Tais elementos nos levam a refletir também sobre o valor econômico da educação, ou seja, de acordo com a compreensão da noção da Teoria do Capital Humano, onde a educação torna as pessoas produtivas.

Segundo Saviani (2008, p.429):

"A crise da sociedade capitalista que eclodiu na década de 1970 conduziu à reestruturação dos processos produtivos, revolucionando a base técnica da produção e conduzindo à substituição do fordismo pelo toyotismo. O modelo fordista apoiava-se na instalação de grandes fábricas operando com tecnologia pesada de base fixa, incorporando os métodos tayloristas da racionalização do trabalho; supunha a estabilidade no emprego e visava à produção em série de objetos estandartizados, em larga escala, acumulando grandes estoques dirigidos ao consumo de massa. Diversamente, o modelo toyotista apóia-se em tecnologia leve, de base microeletrônica flexível, e opera com trabalhadores polivalentes visando à produção de objetos diversificados, em pequena escala, para atender à demanda de nichos especificos do mercado, incorporando métodos como o just in time que dispensam a formação de estoques; requer trabalhadores que, em lugar da estabilidade no emprego, disputem diariamente cada posição conquistada, vestindo a camisa da empresa.

Nessas novas condições reforçou-se a importância da educação escolar na formação desses trabalhadores que, pela exigência da flexibilidade, deveriam ter um preparo polivalente apoiado no dominio de conceitos gerais, abstratos, de modo especial aqueles de ordem matemática. Manteve-se, pois, a crença na contribuição da educação para o processo econômico-produtivo, marca distinta da teoria do capital humano. Mas seu significado foi substantivamente alterado".

De forma complementar a esta análise crítica de Saviani, podemos analisar o discurso presente na obra O Caminho da Servidão, de Hayek (1990), que tenta defender a completa liberdade de mercado sob a lógica capitalista, como um grande benefício para a sociedade de forma geral. O fato é que este ideólogo deixa claro, em sua obra, que a desigualdade social é um mal necessário para a manutenção do sistema que defende. $\mathrm{O}$ objetivo é de que a grande massa se convença de tais preceitos e acredite que a livre concorrência é a medida mais justa para o alcance da ascensão social, eximindo o Estado de qualquer responsabilidade nesse sentido, e transferindo aos indivíduos o ônus de seu possível fracasso profissional e financeiro.

Em outras palavras, de acordo com o discurso intitulado de teoria pós-moderna neoliberal ${ }^{2}$, aqueles que não obtêm êxito econômico, educacional e de saúde (a maior parte da população mundial), assim se encontra por falta de competência e de interesse individual, pois a liberdade de concorrer no mercado propicia "igualdade de oportunidade", a luta de classes aqui é apena um discurso.

Tal cenário da teoria pós-moderna neoliberal, objetiva responder à demanda de mercado capitalista por um "novo trabalhador", adaptado ao just in time $e^{3}$. Desta nova relação de produção, agregam também um aumento de responsabilidade do trabalhador, os acréscimos na jornada de trabalho e a pressão psicológica relacionada à qualificação, configurando uma forma de apropriação de sua subjetividade.

Como vimos anteriormente, apesar de "qualificado", o trabalhador não tem segurança nenhuma de empregabilidade, uma vez que na nova ordem produtiva o trabalho

2Uma reposição do liberalismo econômico adaptado as fases do capitalismo contemporâneo.

3 De acordo com Taiichi Ohno (1997), o just in time busca obter o que é necessário, no momento necessário, na quantidade necessária, tendo-se em vista o aumento da produtividade, a diminuição dos custos e a expansão dos lucros. 
vivo vem perdendo centralidade nas atividades laborais, mesmo que seja uma mão de obra qualificada.

Tal contraditória realidade, além de ser dotada de uma flexibilidade no processo produtivo, implantada pelo toyotismo, torna o indivíduo único responsável por sua formação e ao mesmo tempo por sua empregabilidade. Conforme Saviani (2008, p. 430):

"A ordem econômica atual, denominada de pós-fordista e pós-keynesiana, pressupõe, ou melhor, assenta-se na exclusão, categoria que comparece duplamente: ela é pressuposta, num primeiro sentido, na medida que admite, preliminarmente, que na ordem econômica atual não há lugar para todos. Portanto, boa parte daqueles que atingem a idade para ingressar na População Economicamente Ativa (PEA) nela sequer chega a entrar. Num segundo sentido, a exclusão é pressuposta porque, incorporando crescentemente a automação no processo produtivo, a ordem econômica atual dispensa, também de forma crescente, mão-de-obra. Estimulando a competição e buscando maximizar a produtividade, isto é, o incremento do lucro, a extração de mais-valia, ela rege-se por uma lógica de que estabelece o predominio do trabalho morto (capital) sobre o trabalho vivo, conduzindo à exclusão deliberada de trabalhadores. No neoprodutivismo, nova versão da teoria do capital humano que surge em conseqüência das transformaçóes materiais que marcam a passagem do fordismo ao toyotismo, determinando uma orientação educativa que se expressa na "pedagogia da exclusão".

Constata-se que esse peculiar modo de produção automatizado é uma nova ordem para o mundo do trabalho, no qual a força de trabalho busca qualificar-se pela flexibilização de suas competências e habilidades, adaptando-se a resolver problemas e a assumir várias funções (versatilidade), enfim, todas as habilidades necessárias às novas tecnologias. Focado no indivíduo, o objetivado é capacitar-se para melhor trocar sua força de trabalho, pois a capacidade de trabalhar é o que possui para ser vendido, sendo necessário que ele torne essa "mercadoria” cada vez mais atraente, em um mercado amplamente competitivo. São fundamentais neste contexto as pesquisas de Marx, em cuja opinião "o trabalho não produz apenas mercadorias; produz também a si mesmo e ao trabalhador como uma mercadoria". (2004, p. 159).

Assim a educação e a história articulada aos interesses da sociabilidade do capitalismo tardio, com a roupagem da pós-modernidade direcionado aos ditames das leis de mercado finda por articular a completa mercantilização da vida e potencializa ainda mais a exploração do homem pelo homem.

A ação formativa dos seres humanos vai abandonando, assim, seu caráter transformador e assume-se como fonte de interesses puramente burgueses. Assume-se um referencial completamente mercantil, e a própria cultura se torna um produto a ser comercializado. A história, deste modo, vai perdendo a função social de "produzir, direta e intencionalmente, em cada indivíduo singular, a humanidade que é produzida historicamente e coletivamente pelo conjunto dos homens"(SAVIANI, 2008, p. 17).

Terry Eagleton comenta ainda que "o pós-modernismo, em suma, rouba um pouco da lógica material do capitalismo avançado e a volta agressivamente contra seus funda mentos espirituais" (EAGLETON, 1998, p. 129). Mas essa liberalidade de consumo e crédito não corresponde automaticamente a uma liberdade nas relações humanas, abertura ao diálogo e no reconhecimento do outro: 


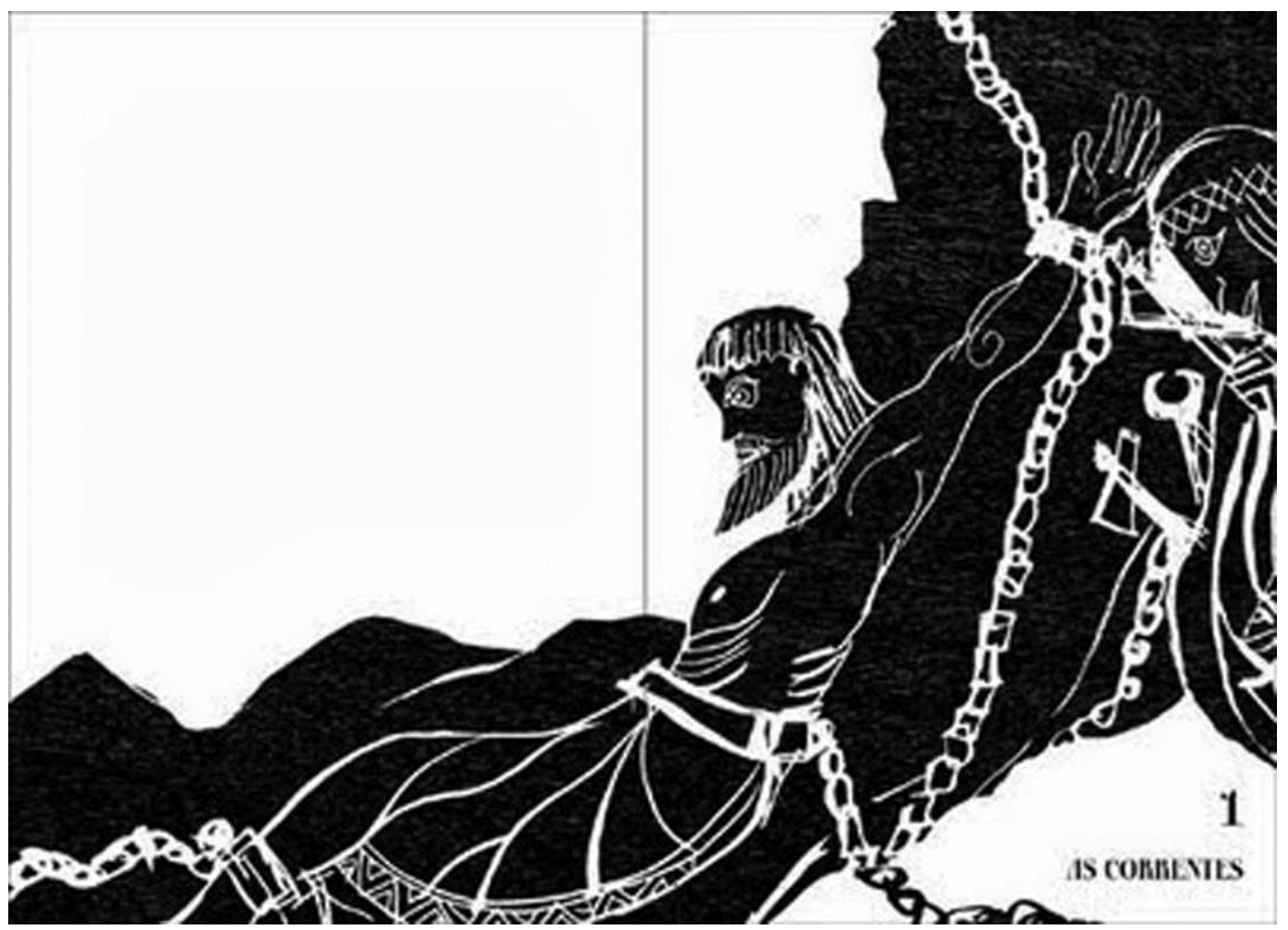

Prometeu acorrentado. Fonte: http://tantettaus.blogspot. com.br/2013/10/o-misterio-de-prometeu.html.

(...) apesar de toda a sua tão alardeada abertura para o outro, o pós-modernismo pode se mostrar quase tão exclusivo e crítico quanto às ortodoxias a que ele se opóe. Você pode falar da cultura humana mas não da natureza humana, de gênero mas não de classe, do corpo mas não da biologia, de fruição mas não de justiça, do pós-colonialismo mas não da burguesia mesquinha. Trata-se de uma heterodoxia de todo ortodoxa, que como qualquer forma imaginária de identidade precisa de seus bichos-papões e alvos imaginários para manter-se na ativa. (...) embora inspire-se no espirito crítico, raras vezes o usa para tratar das próprias proposiçôes" (EAGLETON, 1998, p. 34-35).

Esta ilusão, por exemplo, se articula ainda com os limites e possibilidades dos novos movimentos sociais que põem em xeque a luta por melhores condições de vida, mas não tocam no central da crítica da economia política, ou seja, o fim das distinções de classe social imposta pela lógica do capitalismo. Não se trata apenas, como a maioria acredita, entre eles, PT e demais partidos da chamada esquerda oficial, de mudar pelo voto democrático-burguês a elite política dirigente, pois é necessário radicalmente, via revolução, horizontalizar as relações sociais, objetivando assim, finalmente, extinguir a relações de produção que se alimentam na exploração do homem pelo homem.

Neste sentido, os novos movimentos sociais, apesar de importantes e necessários, perdem de vista a possibilidade histórica de transpor as demandas imediatas, contingenciais como a reforma agrária, quotas, o movimento ecológico, negro, gay, indígena, de saúde, educação, étnico-racial, enfim, o movimento da diversidade dentro da ordem do capital, temáticas bem ao gosto da escrita da história pós-moderna, e ainda, que a pseudoesquerda, mesmo quando veste a roupagem de crítica, em verdade não se configura como opção teórica alternativa ao capitalismo. 
Muito ao contrário, segundo Boron (2003), a capitulação ideológica da maioria dos intelectuais de esquerda é evidente,

"Basta dizer que a formidável hegemonia ideológico-politica do neoliberalismo e a consolidação da 'sensibilidade pós-moderna' contam-se entre os principais fatores, os quais se combinaram para impulsionar uma tendência 'antiteórica' fortemente instalada em finais do século XX. Tudo isso teve o efeito de potencializar extraordinariamente a maciça capitulação ideológica da grande maioria dos intelectuais de esquerda, um fenômeno que adquiriu singular intensidade na América Latina". (BORON, 2003, p.47)

É preciso salientar, entretanto, o limite dessa ação política reformista de luta por cidadania e direitos humanos nos marcos do Estado democrático de direito e não de ruptura anticapitalista. Destacando o entendimento de que a pós-modernidade é característica de uma estrutura social fundamentada na mercantilização da vida por meio de intensiva desigualdade entre as classes sociais. Este fato se camufla em uma sociedade pseudodemocrática, que ilusoriamente mascara e oprime a maioria da população na masmorra da miséria do Estado Capitalista e que, a conta-gotas, permite alguma melhoria ou ascensão social.

Tem-se, assim, o discurso golpista pós-moderno neoliberal, enquanto um canto de sereia, que se apropria dos sujeitos, "educando-os" para atender as necessidades do capitalismo, para ser submisso a um regime que sobrevive da exploração entre os seres humanos.

Como consequências mortíferas das ilusões do canto da sereia pós-moderna na Sociabilidade do Capitalismo Tardio pode-se apontar ainda:

1- Recusa em desenvolver um projeto coletivo de sociedade que contribua para a luta anticapitalista e de emancipação humana.

2- Minimização da importância de uma sólida formação teórica, pois a negação das metanarrativas é necessária a fim de que seja possível buscar múltiplas respostas às incertezas do presente.

3- Negação de categorias como classe, totalidade, contradição é ocasionado pela ênfase no local, no específico, na fragmentação, na heterogeneidade, retirando dos sujeitos a referência no coletivo como fundamento para a ação.

4- A valorização do pesquisador descritivo, ficcional, subjetivista e não analítico das contradições históricas do capitalismo, restringido a reflexões de questões vivenciadas no contexto mais próximo, sem uma orientação que represente um compromisso político mais amplo.

Nestes termos pode-se afirmar, mediante os argumentos apresentados, que é clara a articulação golpista entre os fundamentos do neoliberalismo e da agenda pós-moderna. Desta feita, os dados contemporâneos de precarização/pauperização e baixos índices de escolarização não surgiram ao acaso e permanecem para servir de base à tese de mal-estar social própria de uma sociedade produtora de mercadorias e acumulação desigual de riquezas.

Estes aspectos são fundamentais para uma pesquisa engajada e comprometida com as necessárias transformações das mazelas sociais vigentes em nosso tempo.

Assim, compreendo ser necessária maior centralidade em ações políticas de construção de uma nova ordem social. Nesta linha de raciocínio, conhecer "em seus pormenores" a chamada pós-modernidade é importante para formar nossa consci- 
ência histórica acerca da necessidade de um trabalho educativo crítico e criativo que, associado à luta pela emancipação humana, busque contribuir para revolucionar a sociedade capitalista vigente.

Historicamente, as ruas brasileiras em 2013, campo de disputa política de grupos diversos, oscilando da extrema direita golpista nazifascista aos libertários anarquistas e comunistas, nos educam com um outro canto, de um povo que não se ilude e nem se embriaga com a beleza mortífera da sereia neoliberal pós-moderna capitalista, que diz que tu podes individualmente fazer o que quiseres, pois há de ser tudo de lei.

Não, o coletivamente fazemos e devemos continuar a fazer é a negação radical e autogestionada da sociabilidade do Capital, do Estado e do Mercado.

\section{Referências bibliográficas}

BORON, A. A. Filosofia política marxista. São Paulo: Cortez, 2003.

EAGLETON, Terry. As ilusões do pós-modernismo. Rio de Janeiro: Jorge Zahar Ed., 1998.

FOUCAULT, Michel. Microfísica do Poder. 16ed ${ }^{\mathrm{a}}$. Rio de Janeiro: Graal. 2001. HAYEK, Friedrich August. O caminho da servidão. 5a edição, Rio de Janeiro: Instituto Liberal, 1990.

HOBSBAWN, Eric. Sobre história. São Paulo: Companhia das Letras, 1998. HOMERO. Odisséia. Trad. Odorico Mendes; org. Antônio Medina Rodrigues, pref. Haroldo de Campos. São Paulo: Ars Poetica / EDUSP, 2000.

JAMESON, Fredric. Pós-modernismo - a lógica cultural do capitalismo tardio, São Paulo: Ática, 2002.

MARX, Karl. Manuscritos Econômico-filosóficos. Tradução de Jesus Ranieri, São Paulo: Boitempo: 2004.

MARX, Karl; ENGELS, Friedrich. Manifesto comunista. São Paulo, SP: Boitempo Editorial, 2007.

NIETZSCHE, Friedrich. Assim falou Zaratustra: um livro para todos e para ninguém. 3a ed. Rio de Janeiro: Civilização Brasileira, 1983.

SAVIANI, Dermeval. História das Idéias Pedagógicas no Brasil. 2a . Ed. Campinas, SP: Autores Associados, 2008. (Coleção Memória da Educação).

VILAR, Pierre. Marx e a História. História do Marxismo. 3aed. Rio de Janeiro, 1987. WOOD, Ellen. O que é a agenda "pós-moderna”? In: WOOD, Ellen \& FOSTER, John. Em defesa da história. Rio de Janeiro: Jorge Zahar, 1990.

Artigo recebido em novembro de 2015 e aprovado para publicação em janeiro de 2016. 